\title{
Provision and regulation of food security in conditions of complex epidemiological situation: theoretical and methodological aspect
}

\author{
Alexander Kurdyumov* \\ Ural State Economic University, 620144 Yekaterinburg, Russia
}

\begin{abstract}
The article is devoted to assessing the construction of regulation and ensuring food security at the international and national levels. The object of the study was the methods of regulation and management of socioeconomic effects of AIC regional-sectoral structures, influencing the stability of the food security provision system. The hypothesis of the study is the assertion that the quality of international and national legal regulation positively correlates with the quality of food security provision. The article analyzes the complex of international social and economic institutions in a hierarchical way through the use of institutional methodology. The author analyzes the data illustrating the practice and dynamics of normative-legal provision of the system ensuring food security in the conditions of difficult epidemiological situation. Based on the results of the study, the main trends and directions of development in the field of regulation and ensuring food security in the face of threats and large challenges is evaluated.
\end{abstract}

\section{Introduction}

Now the whole world, which has confidently entered the sixth technological mode, using the benefits of digitalization in many spheres of life in general and economy, shaping the thinking of the new technological society, was exposed to the global challenge in the form of the threat of uncontrolled spread of coronavirus infection COVID-19, which entailed a pandemic, severe quarantine measures and, as a result, to a great extent a halt to economic activity and social interaction of the population and economic entities. These changes affected all countries of the world without exception.

The emerging pandemic of the COVID-19 coronavirus highlighted the problem of countries' security and strategic preparedness against poorly predicted threats of essentially planetary scale. In such circumstances, the problem of ensuring economic and physical availability of environmentally friendly food in scientifically justified volumes and structure for normal life of the country's population becomes central to the national security system.

Many scientists considering the issues of ensuring world food security emphasize the need to maintain a high level of agro-food markets stability with preserving economic and physical availability of basic food for all countries [1-4] .

\footnotetext{
*Corresponding author: kurdyumov@usue.ru
} 
Taking into account that the existing socio-economic differences of countries in the context of complex epidemiological situation significantly increase the risks of providing the world food security, so international institutions are becoming the most important driver in ensuring world food security [5-7].

In these conditions it is necessary to find new scientifically sound adaptive mechanisms for regulating interactions and structural changes throughout the entire agrifood promotion chain (from production to consumption) in the food security system of the State and its regional subsystems.

The scientific problem, to the solution of which the research is directed, is realized in the development of scientific approaches, methodological principles and the formation of tools for construction and effective functioning of a management complex model of socioeconomic effects of AIC regional-sectoral structures in conditions of complex epidemiological situation.

To solve the problem the empirical base is synthesized, methodological approaches are formulated and multilevel complex model of food security is formed in conditions of complex epidemiological situation.

Approbation of the formulated methodological approaches will allow to give a comprehensive assessment to the functioning of socio-economic effects management model of AIC regional-sectoral structures in the conditions of complex epidemiological situation, to identify the main failures in the stages of construction of its institutional and organizational structure, to develop effective state support measures for farmers and the population, to introduce effective methods of state regulation of the economy in the conditions of complex epidemiological situation.

The object of research is the methods of regulation and management of socio-economic effects of AIC regional-sectoral structures, affecting the stability of the system ensuring food security.

The subject of the study is economic and legal relations on the formation of a complex management model of socio-economic effects of AIC regional-sectoral structures and assessment of their impact on the sustainable development of the national food security system in the context of a complex epidemiological situation.

The fundamental scientific problem, to the solution of which the research is directed, is the development of theoretical and methodological bases of a complex management model formation of socio-economic and economic effects of AIC regional-sectoral structures in complex epidemiological situation, and carrying out a comprehensive analysis of the impact of socio - economic effects of AIC regional -sectoral structures for sustainable development of food security system of Russia.

\section{Materials and Methods}

In the article, at each stage of implementation the appropriate methods, approaches of research and information base are used.

Scientific knowledge methods such as direct (empirical) analysis and synthesis, induction and deduction, historical method were used in studying and analyzing scientific problems in accordance with the essence of the subject researched.

In order to collect, compile and analyze socio-economic information on the epidemiological situation impact on the sustainable economy development, as well as to obtain full and comprehensive information about the subject of research, general theoretical and universal methods (method of systematization and classification, method of facts interpretation, method of analysis and synthesis, method of comparison) are applied.

In particular, general theoretical and universal methods (systematization and classification method, analysis and synthesis method, method of analysis and synthesis, 
method of comparisons, method of analogies) and empirical methods (method of observation and fact-finding) were used to develop and justify the classification of international entities.

In the process of scientific-methodological bases substantiation of complex management model construction of AIC regional-sectoral structures socio-economic effects in complex epidemiological situation conditions, as well as the basic principles definition of functioning and re-engineering organizational management structure of socio-economic effects, it is planned to apply general theoretical and universal methods (methods of analysis and synthesis, method of concretization and generalization, method of comparison and contraposition), empirical methods (expert assessments, observations, creation of diagnostic situations, method of experiment, method of hypothesis construction, method of thought experiment construction, delphi technique, method of "decision-tree") and mathematical methods (ranking, modeling).

\section{Results and Discussion}

The unevenness of socio-economic indicators dynamics in the regional-sectoral structure of the country increased even stronger as a result of the complex epidemiological situation.

The interaction of multiple factors, ranging from micropathogenic and individual or population interactions to macroscale environmental, socioeconomic and demographic conditions, entails the development and implementation of various models for the most complete prediction of the epidemiological situation dynamics and their impact on the development of socio - economic relations.

The World Health Organization (WHO) made a statement on December 31st 2019 regarding cases of pneumonia of unidentified etiology in Wuhan, Hubei Province in China. The novel coronavirus (CoViD-19) was identified as the source of the disease by Chinese authorities on January 7, 2020. Ultimately, the International Committee on Virus Systematics on February 11, 2020 referred to severe acute respiratory syndrome coronavirus as SARSCoV-2.

Studies of complex epidemiological situations have spotlike character and do not contain consideration of the epidemiological factors impact on ensuring food security at global and national level [8-10].

A number of scientists have devoted their work to the research of socio-economic effects related to the justification of their regularities with the development of medicine to reduce morbidity and mortality rates in section of regions [11-12].

Highly appreciating the complex contribution of Russian and foreign scientists to the theory of the study question, it should be noted that their scientific works do not limit the scope for scientific research, as a number of aspects and directions in building a sustainable food security system in the face of threats and challenges have not yet been sufficiently addressed and require more detailed study.

Also recognizing the high importance of existing research in the study of AIC socioeconomic effects, and also noting the existence of fundamental approaches to the identification of their interactions with the development of different industries and regions, it is necessary to note the lack of elaboration of a comprehensive management model construction issues of socio-economic effects taking into account the impact of a complex epidemiological situation on sustainable food security.

In modern conditions, particularly relevant are the tasks of improving the predictive and analytical apparatus of strategy developing the socio-economic interaction in the conditions of complex epidemiological situation, in particular mechanisms, methodologies, models and management decisions that provide an opportunity to minimize the economic impact of the pandemic. 
These factors, influencing the sustainability of the national food security system, become relevant when: the study of characteristics, trends and patterns of socio - economic development, study of effective mechanisms and management algorithms of socio-economic systems in conditions of recurrence and inevitability of crisis events accompanied by increased level of risk and uncertainty; identification and classification of regional-sector structures of agro-industrial complex most affected by the pandemic and most in need of effective state support measures at both federal and regional levels; construction of a comprehensive model for the management of socio-economic effects of AIC regionalsectoral structures in conditions of complex epidemiological situation.

The studies of many scientists emphasize the need to form a qualitative and full-fledged system of formal institutions (legal field) for effective international provision and regulation of food security [13-15].

Given the special role in ensuring food security (international and supranational levels) of social and economic institutions, first of all we will study the transformations of the subjects of legal provision and regulation of food security.

The empirical basis for the findings contained in this part of the study was a database synthesized from various sources [16-18].

The following provisions were the prerequisites for the study:

- analysis of socio-economic institutions directly or indirectly regulating the transformation of legal provision and regulation of food security;

- the main focus is on the substantive characteristics of legal support and regulation of food security in the conditions of complex epidemiological situation;

- outside the study there was an analysis of normative-legal regulation of citizens' social and labor rights restriction in the conditions of complex epidemiological situation requiring a separate detailed research;

- any act (decision) adopted, outside of its regulatory impact, is an indicator of institutional will and activity during the relevant period.

Consideration of normative and legal activity of social and economic institutions in the field of ensuring national food security by scientists is carried out from the perspective of scientific knowledge, the essence of which is viewed in all activities of the State. The research analysis showed that a number of scientists take a comprehensive approach to solving the identified problem in order to adapt legal and regulatory framework to new challenges and threats [ 19-21].

In their studies, both foreign and domestic researchers note in the system of indicators one of the significant criteria for the development of international activity of the state in the field of providing food security to be uniform regulations and standards [22-24].

Accordingly, the analysis of international studies within the scope of our research allows to highlight conceptual approaches to solving common problems and challenges of food security. Identified risks and threats of ensuring national food security will serve as prerequisites for formation of agri-food policy strategy of the state and are aimed at increasing management efficiency of socio-economic effects of AIC regional-sectoral structures in conditions of complex epidemiological situation.

Since formal social and economic institutions at the international and national level, forming economic and legal relations, create the foundation for further sustainable system construction of global food security, it seems logical to pay attention to international organizations, which are directly or indirectly engaged in activities related to the provision of food security, as well as the legal instruments governing this area.

Socio - economic institutions, such as the Food and Agriculture Organization (FAO); International Fund for Agricultural Development (IFAD); International Grains Council (IGS); World Trade Organization (WTO); World Food Programme (WFP) play the central role in the international arena of food security provision. 
At the same time, in the pandemic conditions the increasing role of the World Health Organization (WHO) in food safety and nutrition issues should be taken into account. In a situation of deteriorating food security, especially in the decline of physical food availability, households are forced to switch to a less nutritional regime, which increases the risk to the health of the nation.

These international social and economic institutions in the conditions of the complex epidemiological situation associated with COVID-19 take operational political and economic measures of regulation on its level, including:

- FAO has introduced tools to assess the impact of COVID-19 on food and agriculture, supply and distribution chains, food prices, food security worldwide. Participates in the development of measures in response to the potential impact on people's lives and livelihoods, on global food trade, markets.

- Since 1974, IFAD has been one of the UN's specialized organizations for the eradication of rural poverty and focuses on mobilizing financial and economic resources to increase food production and improving the nutritional status of the people below the poverty line in developing countries.

- WHO promotes advocacy to recognize the importance and ensure that everyone has access to safe, healthy and nutritious food.

- The World Food Programme (WFP), in order to promote social and economic development mainly to developing countries, provides humanitarian assistance with food supply, fighting against malnutrition and hunger. In this context, it declares the importance of maintaining food assistance programmes that provide food to vulnerable people around the world.

- The International Grains Council (IGC), as an intergovernmental organization, promotes the development and strengthening of international cooperation in all areas of grain trade including grain exporting and importing countries.

- WTO monitors and regulates trade and political relations of member states of trade agreements, as well as monitors compliance by members of the organization with all agreements signed by the majority countries of the world.

A special role in the conditions of the complex epidemiological situation associated with COVID-19 is played by the effective interaction of the represented international socioeconomic institutions, including the International Monetary Fund (IMF), the International Labour Organization (ILO), the International Bank for Reconstruction and Development (IBRD), the UNCTAD Centre (technical cooperation agency of the UN Conference in Trade and Development (UNCTAD)), the World Food Council and the Committee on World Food Security (CFS).

G-20 countries (G20), based on the situation in the world in connection with COVID-19, highlight the risk of threats to the food security ensuring system on global and national levels as one of the priorities when overseeing the problems of the world.

Finance ministers and heads of central bank of G20 countries at the extraordinary summit on March 26, 2020 decided to invest 5 trillion USD to mitigate the negative impact of the crisis on world economy. They are also considering the adoption of a comprehensive assistance package to developing countries to overcome the social and economic consequences of the pandemic.

In April 2020, FAO, IFAD, WFP, WBRD made a joint statement on the situation with the COVID-19 pandemic and the necessary measures to ensure food security in a complex epidemiological environment situation in the world.

Recognizing the uniqueness of the current situation in the world economy and the unpredictability of the complex epidemiological situation impact on the level of food security in global and national scale, all participants should seek new methodological approaches and 
adaptive mechanisms for the effective management of the socio - economic effects of agro industrial complex, including:

- FAO to develop new measures and tools that will enable countries to mitigate the pandemic's impact on food security and livelihoods worldwide;

- WTO to improve the general principles of international trade and regulation of food prices;

- IGS to amend and clarify the objectives of the Convention, taking into account in a fuller scope the possibilities of stabilizing international grain markets;

- IFAD to develop and implement new mechanisms for the mobilization of financial and economic resources.

- WHO to improve advocacy, including at the social and psychological level, preventing panic responses that can exacerbate disruptions and worsen food security and nutrition of the most vulnerable citizens.

- WFP to improve interaction with all subjects involved in humanitarian assistance to combat hunger and malnutrition.

In view of the emergence of new challenges, the world community faces the question of the transition of countries to a food self-sustainment strategy.

Foreign and domestic scientists are searching for solutions to the problems of ensuring food security, but now taking into account the emergence of new challenges to the optimal model of its provision did not succeed form it.

World practice shows that the main function of regulating food security is assigned to the state. Thus, the main directions of state regulation are: socio-economic and physical accessibility. Economic affordability is evident in price and tariff regulation. Social accessibility - in the level of accessibility of socially disadvantaged groups to food. Physical accessibility is determined by defining the development level of the infrastructure of goods production and is ensured through legal regulation.

Globalization, according to foreign and domestic scientists, is a mechanism that contributes to the development of complex linkages between national food security systems.

The author presents the construction of a complex management model of socio-economic effects of agro-industrial complex in the conditions of complex epidemiological situation in the following form according to hierarchies of a multi-level organization:

- World Food Security - Maintaining stability in food borders in commodity markets with availability of basic food for all countries of the world and assessing it by international socio - economic institutions.

- Food security of the country - a component of national security of the country with the guarantee of physical, economic and social accessibility to quality and safe food for the entire population in compliance with the conditions of sanitary and epidemiological requirements of the national service.

- Food independence of the country is a component of food security of the state and is determined by sustainable reproduction of domestic agro-industrial complex no lower than established state food criteria. And becomes dependent on the effectiveness of interregional relations and the state support policy of the subjects of the Russian Federation.

- Food self-sufficiency of the region - the basic component of food independence of the country, determined by the production of basic food of its own production not lower than established regional food criteria.

- Household food security is the lowest level of the model that addresses the food problem.

Within the framework of this model, a mechanism that takes into account communication systems contributing to ensuring world food security through regulatory regulation should be developed. 
New challenges and threats of multi-level complex of socio-economic relations of individual countries have a significant impact on the formation of a unified sustainable global system of food security provision. This feature creates the difficulty of developing a single universal mechanism, which makes this issue relevant.

Accordingly, in the face of mature market relations and increasing competition in the face of increasing risks and uncertainty, a new approach to developing global food supply security is needed.

At the national level, the food security system needs a new target, based on international solidarity, expressed in common understanding and standards, allowing to achieve an effective response of Russian society to great challenges taking into account the interaction of man and nature, man and technology, social institutions at the present stage of global development.

The obtained data illustrate the practice of social and economic relations in the field of food security and determine the feasibility of their use in a separate study of transformations of the Russian system of ensuring food security.

\section{Conclusions}

To summarize this study, we will note some important trends in the regulation and provision of food security at the world and national levels in a complex environment of the epidemiological situation:

- world experience in ensuring food security shows that the role of effective interaction between international organizations is increasing;

- central place is given to the state and its pricing policy in the domestic market.

This scientific article analyzes the processes illustrating the practice and dynamics of building a sustainable international and national system of ensuring food security in conditions of complex epidemiological situation.

The scientific novelty of the research lies in the following provisions:

- the classification of international social and economic institutions providing world food security in the conditions of complex epidemiological situation has been developed and substantiated;

- developed a complex model of management of socio-economic effects of agro-industrial complex in conditions of complex epidemiological situation in accordance with the hierarchy of multilevel organization.

Scientific significance of the results of the study will contribute to further development of theoretical and methodological bases of a sustainable system formation for ensuring food security at the emergence of threats and large challenges. It is possible to use the results for further development of theoretical and empirical research in the management field of socioeconomic effects of agro-industrial complex and their impact on sustainable food security of the country in the context of a complex epidemiological situation.

\section{Acknowledgment}

The reported study was funded by RFBR, project number No. 20-04-60496 «Formation of an integrated model of management of socio-economic effects and assessment of their impact on sustainable development of the economy in conditions of difficult epidemiological situation», No. 19-010-00886 «The comprehensive economic and legal study of improving the competitiveness of the agro-industrial complex of the Russian Federation in the context of the development and integration of information-digital systems». 


\section{References}

1. A.I. Altukhov, Paradigm of food security of Russia, monograph.: Moscow. Publishing house: Youth Development and Support Fund "Personnel Reserve", 685 (2019)

2. V.M. Pizengoltz, Problems of food and economic security of Russia: theory, methodology, practice, 252 (Moscow. Publishing house: Russian New University, 2019)

3. Diana J. Mason, Jama-journal of the American medical association, 323, 406 (2020)

4. Zahra Ardakani, Fabio Bartolini, Gianluca Brunori, Agriculture-basel, 10, 74 (2020)

5. V.S. Balabanov, E.N. Borisenko, Food security: international and domestic aspects, Russian Academy of Entrepreneurship, 247 (Moscow: Economics, 2012)

6. Ivar Vagsholm, Naser Shah Arzoomand, Sofia Boqvist, Frontiers in sustainable food systems, 4, UNSP 16 (2020)

7. T.M. Yarkova, Food security: Russian experience and foreign practice, monograph: 192 (Moscow, Publishing house: IPC Prokrost, 2019)

8. Jingjing Yuan, Yonglong Lu, Xianghui Cao, Cosystem health and sustainability, 6, UNSP 1741325 (2020)

9. C. Huang, Y. Wang, X. Li, L. Ren, J. Zhao, Y. Hu, et al. The Lancet, 395, 10223, 497 (2020) doi 10.1016/S0140-6736(20)30183-5

10. J.F. Chan, S. Yuan, K.H. Kok, K.K. To, H. Chu, J. Yang, et al. The Lancet, 395, 10223, 514 (2020) doi 10.1016/S0140-6736(20)30154-9

11. A.I. Ovod, Azimut of Scientific Research: Economics and Management, 7, 1 (22), 211 (2018)

12. K. Amlaev, E. Khoroshilova, Vrach, 29, 1, 85 (2018)

13. M. Kislitsky, Transformation of conditions and economic relations in the system of providing the population with food (Moscow, Publishing house: All-Russian Research Institute of Agricultural Economics), 260 (2018)

14. A.N. Syomin, Agriculture Economics of Russia, 1, 55 (2020)

15. A.I. Altukhov, A.N. Semin, E.I. Semenova, M.M. Kislitsky, A.E. Borodkin, Agrifood sector of Russia in the conditions of "big challenges": problems, risks, new opportunities, 416 (Moscow, Publishing house: "Personnel Reserve" Fund 2019)

16. V.D. Goncharov, Zh.A. Akhmedova, M.V. Selina, Food security of Russia, monograph: Moscow. Publishing house: Agricultural Technologies, 177 (2018)

17. A.N. Semin, A.P. Tretyakov, Agrarian sector of economy in the system of the state food security (Yekaterinburg. Publishing house:Limited Liability Company "Ural Publishing House", Yekaterinburg), 158 (2016)

18. Olga Yu. Frantsisko, Kristina O. Ternayshchenko, Alexey S. Molchan, Amazonia investiga, 9, 59 (2020)

19. Isabel Novo-Corti, Diana-Mihaela Tirca, Magdalena Ziolo, Xose Picatoste, Sustainability, 11, 336, (2019)

20. John Mendy, Mahfuzur Rahman, P. Matthijs Bal, Thunderbird international business review, 62, 199 (2020)

21. Inna Irtyshcheva, Maryna Ponomarova, Iryna Dolzhykova, Baltic journal of economic studies, 5, 2, 57 (2019)

22. A.V. Kurdyumov, Technology and Merchandizing of Innovative Foodstuf, 2 (31), 106 (2015)

23. A.N. Semin, Economics of agricultural and processing enterprises, 5, 9 (2015) 
24. A.I. Altukhov, V.V. Drokin, A.S. Zhuravlev, Increasing competitiveness the agro-food complex is impossible without its rational territorial organization, IOP Conference Series: Earth and Environmental Science, 012005 (2019) 